\title{
Public health vulnerability to climate change in Brazil
}

\author{
U. E. C. Confalonieri* ${ }^{*}$ D. P. Marinho, R. E. Rodriguez \\ Program on Global Environmental Changes and Health (PMAGS), National School of Public Health, \\ Oswaldo Cruz Foundation (FIOCRUZ), Avenida Brasil 4036/703, Manguinhos, Rio de Janeiro RJ, CEP 21040-361, Brazil
}

\begin{abstract}
A national quantitative assessment of the current vulnerability of the Brazilian population to the health impacts of climate change was undertaken with the support of the Brazilian Ministry of Science and Technology. A conceptual framework of vulnerability in the health sector, according to a modified general 'exposure-response' model, was adopted (Confalonieri 2003). For the quantification of vulnerability, a new methodology was used to develop a synthetic (composite) general vulnerability index from averages of specific indices of vulnerability in 3 areas: socio-economic, epidemiological and climatological. We found that the greatest influence on the general vulnerability index (of the most vulnerable states) was from the socio-economic vulnerability index. The approach used also demonstrated that the northeast is the most vulnerable Brazilian region to the health impacts of a changing climate.
\end{abstract}

KEY WORDS: Vulnerability $\cdot$ Health $\cdot$ Climate change $\cdot$ Assessment $\cdot$ Brazil $\cdot$ Methods

\section{INTRODUCTION}

Future scenarios of carbon-driven anthropogenic changes in the global climate system project an increase in climate extremes, meaning an increased risk of disease and injury to the population, particularly to the most vulnerable groups (IPCC 2001, 2007).

Vulnerability is the result of complex interactions involving both physical and social processes, and the need for the development of national plans of adaptation to a changing climate has stimulated the undertaking of more formal assessments of differential levels of vulnerability. Vulnerability to the impacts of weather and other disasters has been defined as 'the characteristics of a group or a person related to their capacity to anticipate, to cope with, resist and recover from the impacts of natural hazards' (Blaikie et al. 1994). It follows that the most vulnerable social groups are those that experience the most exposure to a hazard, that are the most sensitive to it, and have the weakest capacity to respond and ability to recover. Vulnerability to global environmental changes is also distinguished as both a biophysical condition (geo- graphic space) and is defined by political, social and economic conditions (Liverman 1990).

Brazil, because of its geographical characteristics, the continental size of its territory, its climatic profile, its large population and its structural social problems, may be considered an area vulnerable to the impacts of a changing climate on human health. Also, the persistence of endemic infectious diseases sensitive to climate variability, such as malaria, dengue fever and leptospirosis - as well as of other conditions that determine the overall population health status - contribute to shape the vulnerability of the population (Few 2007).

In this study we propose a new methodology for the quantitative assessment of the population vulnerability to the health impacts of climate. The aim of the present study was to provide a general and comparative regional assessment of the structural factors that contribute to the social-environmental vulnerability in the face of climate-change impacts. Indicators were used, since, in addition to being a standard procedure in public health assessments, they are increasingly being utilized in vulnerability assessments (Adger et al. 2004, Bhadwal 2006, Eriksen \& Kelly 2007). 
We characterized the current vulnerability of Brazil using - as health impacts — climate-sensitive infectious diseases of public health concern, and-as social impacts-factors that determine a poor response to climate-related hazards. The historical health situation was used to show the trends in incidence and impacts (i.e. mortality and health care costs) of the diseases in recent years. It was assumed that the main changes (in terms of frequency and magnitude) in climate-related health hazards will result from changed average values for temperature and precipitation, and from alterations in the patterns of extreme climatic events. The characterization of vulnerability may be subsumed to the policy-making process, with the objective of adaptation to a changing climate. Current vulnerabilities may, in part, continue into the future, and could (potentially) be reduced by appropriate policies.

The methodological-theoretical framework was adopted from a previous study (Confalonieri 2003); it was based on a general 'exposure-response' model (Watts \& Bohle 1993). A set of proximate drivers of vulnerability was identified, ranging from individual characteristics such as age, gender and physical capacity to social-environmental characteristics such as geographical aspects (e.g. place of residence), institutions and general infrastructure. One set of proximate drivers was responsible for the magnitude and timing of human exposures to climatic hazards (Fig. 1, top right) and another set (Fig. 1, bottom left) modulated the capacity and effectiveness of the responses to the impacts resulting from exposures. Both sets of determinants were, in turn, conditioned by structural characteristics such as education, income, governance and political power, which were called 'primary' or 'ultimate' drivers of vulnerability. Morbidity and mortality are undesirable consequences, and result from a poor social response to the adversities of climate (Fig. 1).

Other studies have based vulnerability frameworks on elements such as perturbation stress and coupled socio-ecological systems (Turner et al. 2003, Kasperson et al. 2005). A recent review called for an interdisciplinary conceptualization of vulnerability, based on the themes of poverty/exclusion and social-environmental interactions (Hogan \& Marandola 2005). All of these, however, acknowledge that although social and economic issues are of paramout importance in determining vulnerability, environmental factors also play an important role. The conceptualization used in this paper also recognizes these factors, although we did not quantify environmental characteristics other than trends in precipitation.

\section{APPROACH}

An index was developed for each dimension (socioeconomic, epidemiological and climatological) analyzed in the present study. The socio-economic vulnerability index (IVSE) was developed for the quantification of

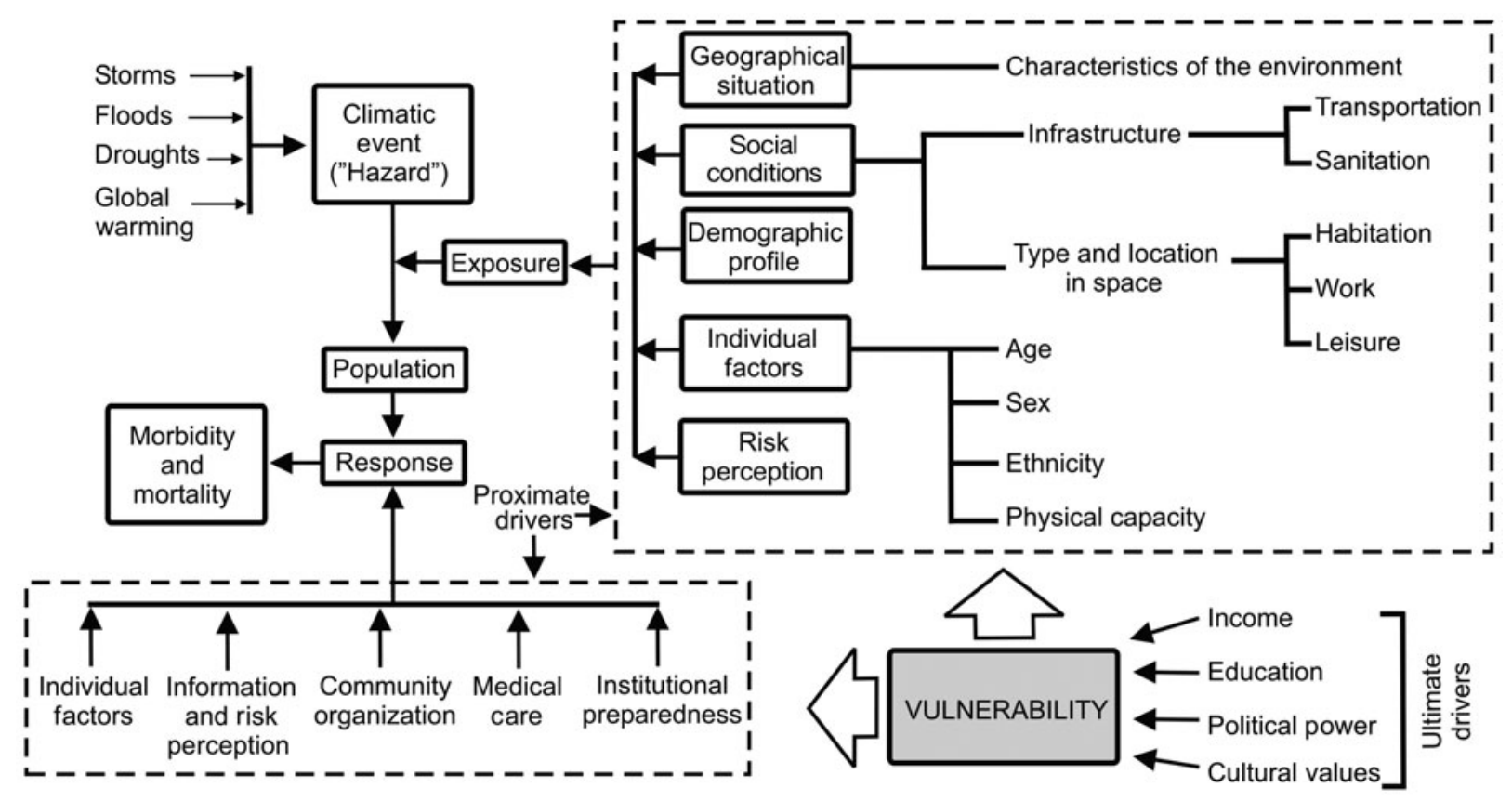

Fig. 1. Conceptual model for vulnerability to health impacts of climate 
social and economic factors, originally collected as primary data by the Brazilian Government. An epidemiological vulnerability index (IVE) was constructed from morbidity, mortality and health costs data, related to 7 climate-sensitive endemic infectious diseases occurring in Brazil. The climatological vulnerability index (IVC) was developed from historical precipitation data, representing weather extremes.

\subsection{Synthetic indicators}

The synthetic indicators have, as their main function, the concentration of information in just one variable. This allows for comparisons of elements, individuals and units, both at spatial as well as temporal levels. One example is the United Nation's human development index (HDI), which was created to measure the level of human development in different countries, using education, income and life expectancy as indicators. HDI values range from 0 (no development) to 1 (complete human development). The indices developed in the present paper were meant to indicate the state of the as-yet-unmeasured vulnerability of the 26 Brazilian states, plus the Federal District, to the impacts of a changing climate, from a public health perspective.

These indices were elaborated from a comprehensive set of simple indicators related to the vulnerability concept adopted as the framework for our research. These were classified into 3 major areas: socio-economic, epidemiological and climatological.

All indicators were transformed (standardized) to indices with values ranging from 0 to 1 , with the higher values indicating a greater vulnerability. To achieve this we determined the relationship between the value of each indicator and the magnitude of the vulnerability. Thus, standardized indices were classified either as Type I, if a high value of an indicator represented a situation of less vulnerability, or, alternatively, as Type II, if the low value of the indicator was associated with a situation of less vulnerability.

The following formulae were used for the standardization of the selected indicators:

$$
\text { Type I: }
$$

Type II:

$S I_{s}=\frac{\max (I)-I_{S}}{\max (I)-\min (I)}, s=1, \ldots, S \quad S I_{s}=\frac{I_{S}-\min (I)}{\max (I)-\min (I)}, s=1, \ldots, S$

where $I_{S}$ is the observed value of the indicator $I$ for the ' $n$ th' state, $S$ is the total number of states compared and $s$ indicates a particular state individually. $S I_{S}$ is the standardized indicator; $\min (I)$ is the smallest value observed, among all states, of the indicator $I$ and $\max (I)$ is the highest observed value of the indicator $I$, among all Brazilian states.
After all standardized indicators were obtained, arithmetic means were calculated for the values of the indicators in the same dimension. Therefore, the indices for each dimension were obtained using the following formula:

$$
\operatorname{dimension}_{s}=\frac{1}{n} \sum_{i=1}^{n} S I_{i, s}, s=1, \ldots, S
$$

The vulnerability indices were defined as linear combinations (arithmetic or weighted means) of the synthetic indicators of different dimensions. Thus, each dimension of the vulnerability had the same relative importance (weight) for the quantitative assessment of the overall vulnerability. All indices range from 0 to 1 ; if a given index is equal to 0 , this means that the corresponding area (state) has better conditions (regarding this index) than the other states, for the same period of time. However, it should be stressed that if an index is 0 , it does not mean that there is no vulnerability; the values of 0 and 1 for the indices represent the best and worse relative situations. The indices developed do not measure the degree of vulnerability of ideal or theoretical situations, but rather were intended to show the relative ranking of Brazilian states with regards to their vulnerability.

\subsection{Socio-economic vulnerability index}

The IVSE was developed to measure the degree of vulnerability of each state, on a comparative basis. The IVSE was elaborated using 11 simple indicators, classified into 5 different dimensions: (1) demography: demographic density (inhabitants $\mathrm{km}^{-2}$ ) and degree of urbanization (\%); (2) income: households with > 2 persons per room (\%) and poverty level (\%); (3) education: degree of schooling ( $\%$ of the population $>15 \mathrm{yr}$ with $<4$ yr schooling); (4) sanitation: piped water supply (\% of households), sewage treatment ( $\%$ of households) and garbage disposal (\% of households) and (5) health: infant mortality rates (per 1000 live births), life expectancy at birth (in yr) and health insurance coverage (\% of population with cover). Table 1 shows the definition of each of the indicators used to elaborate the IVSE. The IVSE is the result of the arithmetic means of the indices calculated for each of the 5 dimensions included:

$$
\begin{aligned}
\text { IVSE }_{s} & =\frac{1}{5}\left(\text { demog }_{s}+\text { income }_{s}+\text { education }_{s}\right. \\
& \left.+ \text { sanit }_{s}+\text { health }_{s}\right), s=1, \ldots, S
\end{aligned}
$$

where demog, income, education, sanit and health represent the indices obtained with the standardized indicators of the dimensions 'demography', 'income', 'education', 'sanitation' and 'health', respectively. 
Table 1. Socio-economic indicators. IBGE: Fundação Instituto Brasileiro de Geografia e Estatística (www.ibge.gov.br/servidor_arquivos_est/); IDB: Indicadores e Dados Básicos para a Saúde (Ministério da Saúde) (http:tabnet.datasus.gov.br/cgi/idb2008/matriz. $\mathrm{htm})$

\begin{tabular}{|c|c|c|}
\hline Definition & Units & Source \\
\hline \multicolumn{3}{|l|}{ Demography } \\
\hline Demographic density & Inhabitants $\mathrm{km}^{-2}$ & IBGE (2000) \\
\hline Degree of urbanization & $\%$ & IDB (2002) \\
\hline \multicolumn{3}{|l|}{ Income } \\
\hline $\begin{array}{l}\text { Households with }>2 \\
\text { persons per room }\end{array}$ & $\%$ & IBGE (2000) \\
\hline Poverty & $\%$ & IDB (2002) \\
\hline \multicolumn{3}{|l|}{ Education } \\
\hline$<4$ yr of school attendance & $\%$ & IDB (2002) \\
\hline \multicolumn{3}{|l|}{ Sanitation } \\
\hline Piped water supply & $\%$ & IBGE (2000) \\
\hline Sewage treatment & $\%$ & IBGE (2000) \\
\hline Garbage disposal & $\%$ & IBGE (2000) \\
\hline \multicolumn{3}{|l|}{ Health } \\
\hline Infant mortality rate & Per 1000 live births & IDB (2002) \\
\hline Life expectancy at birth & yr & IDB (2002) \\
\hline Health insurance coverage & $\%$ & IBGE (2000) \\
\hline
\end{tabular}

\subsection{Epidemiological vulnerability index}

The IVE was developed with the objective of synthesizing, in just 1 composite index, the information contained in a group of indicators related to 7 endemic diseases sensitive to climate variability. The data referred to the period 1996-2001, for each Brazilian state. The diseases were: cholera, dengue fever, malaria, leptospirosis, visceral leishmaniasis, cutaneous leishmaniasis and hantavirus pulmonary syndrome. The selected indicators were: (1) incidence rate, (2) number of hospital admissions in the state/number of hospital admissions in the country, (3) cause-specific mortality in the state/cause-specific mortality in the country and (4) total cost $(\mathrm{R} \$)$ of hospital admissions in the state/total cost $(\mathrm{R} \$)$ of hospital admissions in the country. In the case of malaria, we used the 'annual parasite rate' (IPA). For all endemic diseases-except hantavirus pulmonary syndrome-we decided not to use the absolute observed number of hospital admissions, hospital deaths or costs, but rather the proportion of these variables for each state, in relation to the national totals. In the case of hantavirus infections, since it is a disease that has recently emerged in the country, records only exist for the number of cases and incidence rates. Therefore, since the indicators were calculated using 6 yr of data, 24 indices were developed for cholera, dengue fever, malaria and leptospirosis; 30 for leishmaniasis; and 6 for hantavirus infections.

In the case of the epidemiological vulnerability, we considered each endemic disease to be 1 dimension. The index for each disease is the simple mean of the averaged indicators. As a consequence, we calculated 1 synthetic index for each disease, varying in value from 0 to 1 . The worst relative conditions for each index corresponded to values close to 1.

The IVE was calculated from the individual indices for each disease. Since each disease has its own characteristics, which differ from those of the other diseases, we decided to assign a weight to each, based on the authors' expert judgment. The final weight for a given disease reflected the main characteristics of its natural history determining its public health importance. These characteristics are: (1) possibility of reduction of involuntary exposures (individual protection through behavioral changes), (2) efficiency of environmental control, (3) occurrence of drug resistance, as one possible determinant of treatment failures, (4) possibility of etiological treatment (efficiency of existing drugs) and (5) fatality rates. Environmental control is related to the possibility of reducing risk by changing the environmental conditions. For example, eliminating breeding sites for the mosquitoes that transmit dengue fever in urban areas is feasible, but the same tactic would be impossible for vectors that transmit malaria in the Amazon forest.

Table 2. Structure of the weighting attributed to each disease. Status codes (except fatality rates and total) - 1: good 2: medium; 3: poor. Codes for fatality rates $-1:-10 \% ; 2: 11-39 \% ; 3:>40 \%$. Leish.: leishmaniasis

\begin{tabular}{|c|c|c|c|c|c|c|}
\hline Disease & $\begin{array}{l}\text { Reduction of the } \\
\text { involuntary exposition }\end{array}$ & $\begin{array}{l}\text { Efficiency of environ- } \\
\text { mental control }\end{array}$ & $\begin{array}{c}\text { Existence of } \\
\text { drug resistance }\end{array}$ & $\begin{array}{l}\text { Possibility of etio- } \\
\text { logical treatment }\end{array}$ & $\begin{array}{l}\text { Fatality } \\
\text { rates }\end{array}$ & $\begin{array}{c}\text { Total (final } \\
\text { weight) }\end{array}$ \\
\hline Cholera & 1 & 1 & 1 & 3 & 1 & 7 \\
\hline Dengue & 1 & 1 & 1 & 3 & 1 & 7 \\
\hline Malaria & 3 & 3 & 3 & 1 & 1 & 11 \\
\hline Leptospirosis & 1 & 1 & 1 & 1 & 1 & 5 \\
\hline Leish. cutaneous & 2 & 2 & 1 & 1 & 1 & 7 \\
\hline Leish. visceral & 2 & 2 & 3 & 1 & 1 & 9 \\
\hline Hantavirus & 3 & 2 & 1 & 3 & 3 & 12 \\
\hline
\end{tabular}


For calculation of the weighting of diseases, one of the following values was attributed to each: 1, 2, 3 (good, medium or poor conditions, respectively), according to the known natural history and control strategies of the disease, with regards to the characteristics analyzed. The diseases with the higher weights have the greatest influence in the development of the IVE.

In Table 2 the values attributed to each disease are shown, for each characteristic, as well as the final weight (last column) used for the calculation of the IVE. We observed that the highest final weights were attributed to malaria (11) and hantavirus pulmonary syndrome (12); this means that these are the diseases presenting the greatest risk for the population and/or having the least probability of effective control. The calculation of the IVE used the following formula:

$$
\begin{aligned}
& I V E_{s}=\frac{1}{51} \text { (7choler }_{s}+7 \text { deng }_{s}+11 \text { malar }_{s}+\text { fleptos }_{s}+9 \text { leishm }_{s} \\
& \left.+7 \text { leishmcut }_{2}+12 \text { hanta }_{s}\right), s=1, \ldots, S
\end{aligned}
$$

where choler, deng, malar, leptos, leish, leishmcut and hanta refer to the indices obtained from the standardized indicators for cholera, dengue fever, malaria, leptospirosis, visceral leishmaniasis, cutaneous leishmaniasis, and hantavirus, respectively.

\subsection{Climatological vulnerability index}

Brazil has important regional differences in relation to its climate (Nimer 1989). The northern and southern regions have a fairly homogeneous climate, but high heterogeneity exists in the climate of the northeastern and southeastern regions. The northern, northeastern and central-western regions are hot (all months with averages $>18^{\circ} \mathrm{C}$ ), while the southeastern region is sub-hot (average temperature of the coldest month $<18^{\circ} \mathrm{C}$ ) and wet or semi-wet. The southern region is a mesothermic, very wet, temperate area. Most of the central-western region has a 4 to 5 mo dry period (semi-wet). In the northern region, rainfall regimes vary from very wet (no dry season) to semi-wet. The northeastern region is mostly semi-arid, with dry periods varying 6 to $11 \mathrm{mo}$.

Future scenarios of climate change for different regions of South America and Brazil have recently been developed (Grimm \& Natori 2006, Vera et al. 2006, Marengo 2007). The main objective of the present assessment of climatological vulnerability was to classify the federal states according to the number of months of extreme precipitation, either higher or lower than the historical means. The aim was not to assess the total precipitation, but rather the number of months showing anomalous precipitation levels.

Precipitation data were obtained from the Center for Weather Prediction and Climate Studies (CPTEC/ INPE); the time series corresponded to $42 \mathrm{yr}$ of data. These data resulted from interpolation of data from the National Institute of Meteorology (INMET) and State Departments of Meteorology. Data were interpolated for a $0.25 \times 0.25^{\circ}$ grid (around $25 \times 25 \mathrm{~km}$ ) for the visualization and development of the time series of the accumulated value for each state. Time series of the total monthly precipitation for each state were used; the data period ranged from January 1961 to December 2003 (a total of 504 observations, 42 for each month).

An extreme precipitation value was defined as a value much higher or much lower than those from a historical series. Due to their simplicity, box plots were used to identify these values, as they constitute a common tool for the identification of 'outliers', taking into account the asymmetry and variability of a given data set. The outliers were those values either higher than the sum of the third quartile plus 1.5 times the interquartile distance (i.e. difference between the first and third quartiles) or lower than the first quartile minus 1.5 times the interquartile distance of the sample. Monthly precipitation records were used for each state, and the indicator developed was the percentage of months with extreme precipitation. The IVC was developed to vary from the greatest vulnerability, that is, with the largest number of months with extreme precipitation levels, to the smallest.

The presence of extremely low precipitation values did not mean that no rain was measured. A state with a pattern of high annual precipitation may have had extremely low relative values. This was the case for Amazonas, in the northern region, which has a historical mean precipitation for June of $158.2 \mathrm{~mm}$, but, in June 1997, the observed precipitation of $66.8 \mathrm{~mm}$ was very low in comparison to this mean.

On the other hand, a state with a pattern of low precipitation and long drought periods, such as Piauí, did not show low relative values, since the low precipitation mean observed for August (10.0 mm) was not atypical for that area or period.

By analogy, an extremely high precipitation value did not necessarily indicate flooding. For example, in the state of Pará, the mean value for March during the period of study was $200 \mathrm{~mm}$, which was not an uncommon level. On the other hand, Piauí, which was affected by droughts in July and August, had a precipitation level in August 1983 of $70.6 \mathrm{~mm}$, a value $>10$-fold the historical mean for that month. 
Table 3. Vulnerability indices by Brazilian state: IVSE: socioeconomic, IVE: epidemiological, IVC: climatological and IVG: general

\begin{tabular}{|lcccc|}
\hline State & IVSE & IVE & IVC & IVG \\
\hline Acre - AC & 0.53 & 0.06 & 0.00 & 0.20 \\
Alagoas - AL & 0.76 & 0.16 & 1.00 & 0.64 \\
Amazonas - AM & 0.48 & 0.10 & 0.01 & 0.20 \\
Amapá - AP & 0.30 & 0.10 & 0.23 & 0.21 \\
Bahia - BA & 0.62 & 0.30 & 0.46 & 0.46 \\
Ceará - CE & 0.61 & 0.12 & 0.55 & 0.43 \\
Distrito Federal - DF & 0.18 & 0.02 & 0.32 & 0.17 \\
Espírito Santo - ES & 0.25 & 0.03 & 0.41 & 0.23 \\
Goiás - GO & 0.24 & 0.03 & 0.32 & 0.20 \\
Maranhão - MA & 0.75 & 0.15 & 0.55 & 0.48 \\
Minas Gerais - MG & 0.25 & 0.13 & 0.23 & 0.21 \\
Mato Grosso do Sul - MS & 0.23 & 0.14 & 0.05 & 0.14 \\
Mato Grosso - MT & 0.31 & 0.08 & 0.28 & 0.22 \\
Pará - PA & 0.49 & 0.31 & 0.01 & 0.27 \\
Paraíba - PB & 0.67 & 0.11 & 0.23 & 0.34 \\
Pernambuco - PE & 0.59 & 0.23 & 0.50 & 0.44 \\
Piaú - PI & 0.73 & 0.07 & 0.41 & 0.41 \\
Paraná - PR & 0.22 & 0.13 & 0.19 & 0.18 \\
Rio de Janeiro - RJ & 0.21 & 0.09 & 0.37 & 0.22 \\
Rio Grande do Norte - RN & 0.51 & 0.11 & 0.32 & 0.32 \\
Rondonia - RO & 0.38 & 0.11 & 0.05 & 0.18 \\
Roraima - RR & 0.38 & 0.10 & 0.23 & 0.24 \\
Rio Grande do Sul - RS & 0.17 & 0.13 & 0.10 & 0.13 \\
Santa Catarina - SC & 0.15 & 0.08 & 0.32 & 0.19 \\
Sergipe - SE & 0.52 & 0.10 & 0.55 & 0.39 \\
São Paulo - SP & 0.10 & 0.20 & 0.32 & 0.21 \\
Tocantis - TO & 0.48 & 0.08 & 0.28 & 0.28 \\
\hline
\end{tabular}

\section{RESULTS}

This section begins with the individual analyses of the indices, as well as with the classification of the federal states, according to their respective indices. In the final sub-section we present IVG values and the classification of the Brazilian states obtained from the calculated IVGs.

Table 3 and Figs. 2, 3 \& 4 depict the synthetic indices calculated for the 3 components studied: socio-economic, epidemiological and climatological.

\subsection{Socio-economic vulnerability}

The states with the highest demographic densities were Rio de Janeiro (328.6 inhabitants $\mathrm{km}^{-2}$ ), the Distrito Federal (353.5 inhabitants $\mathrm{km}^{-2}$ ) and São Paulo (149 inhabitants $\mathrm{km}^{-2}$ ), while the states with the lower population densities were in the northern part of the country: Roraima (1.4 inhabitants $\mathrm{km}^{-2}$ ) and Amazonas (1.8 inhabitants $\mathrm{km}^{-2}$ ). All states had $>60 \%$ of their populations living in urban areas, and Rio de Janeiro had the highest urbanization rate $(97 \%)$. With regards to the percentage of households with 2 or more persons per room, this applied to $>10 \%$ of the households in 4 northern states (Acre, Amazonas, Pará and Amapá).

\subsection{General vulnerability index}

The IVG is the arithmetic mean of the 3 other vulnerability indices calculated: IVSE, IVE and IVC.

The IVG for the states is given by the formula:

$\mathrm{IVG}_{s}=\frac{1}{3}\left(\mathrm{IVSE}_{s}+\mathrm{IVE}_{s}+\mathrm{IVC}_{s}\right), s=1, \ldots, S$

All component indices have values ranging from 0 to 1 ; the value 0 indicates the least vulnerable situation and the value 1 shows the most vulnerability. The IVG, also ranging from 0 to 1 , represents the relative vulnerabilities.

The secondary data analyzed corresponded to the Brazilian states plus the Federal District. The socio-economic data were obtained from the National 2001 Census available from the Brazilian Institute for Geography and Statistics (www.ibge.gov.br), as well as from the 2002 'Indicadores e Dados Básicos para a Saúde' (IDB). The epidemiological data and indicators were obtained from the Federal and State Departments of Health.

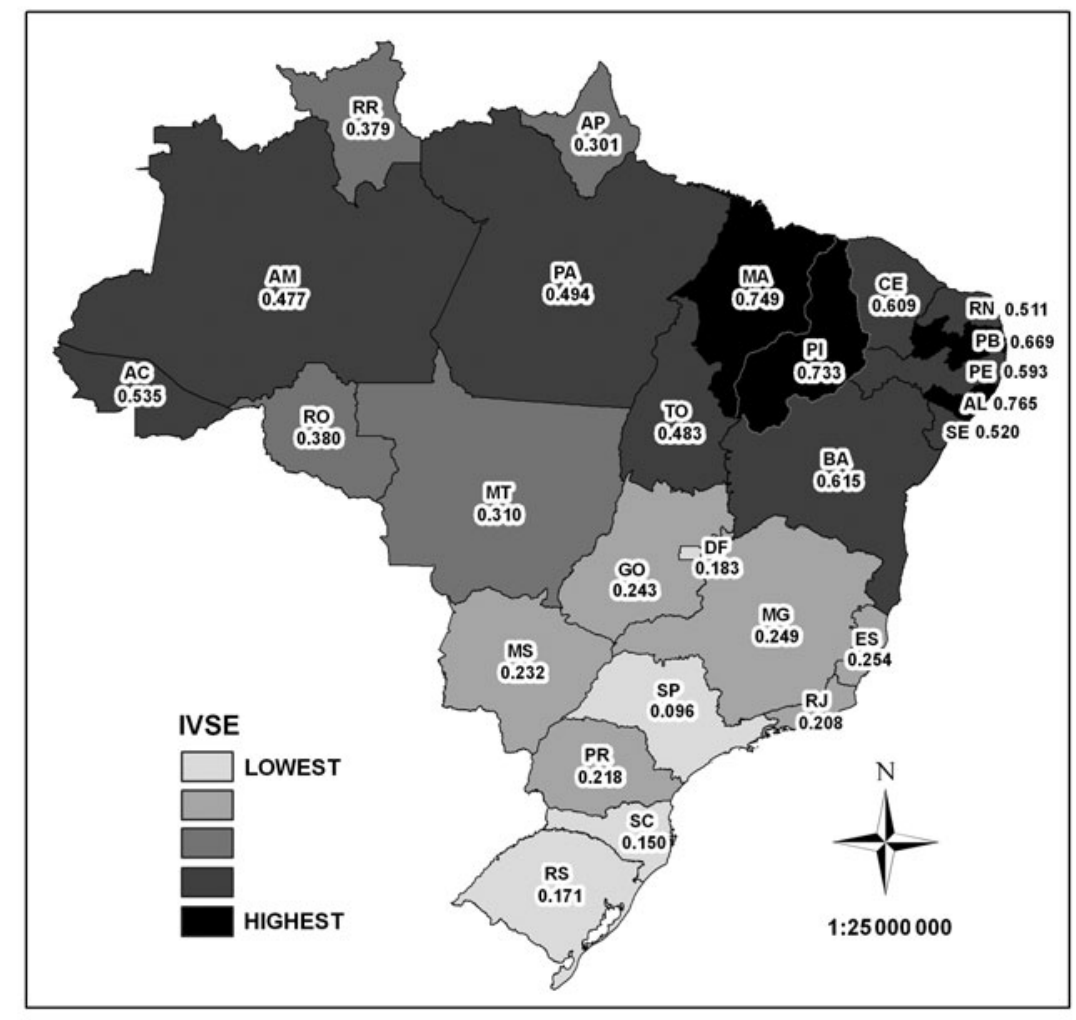

Fig. 2. Socio-economic vulnerability index (IVSE) by Brazilian state (abbreviations in Table 3) 


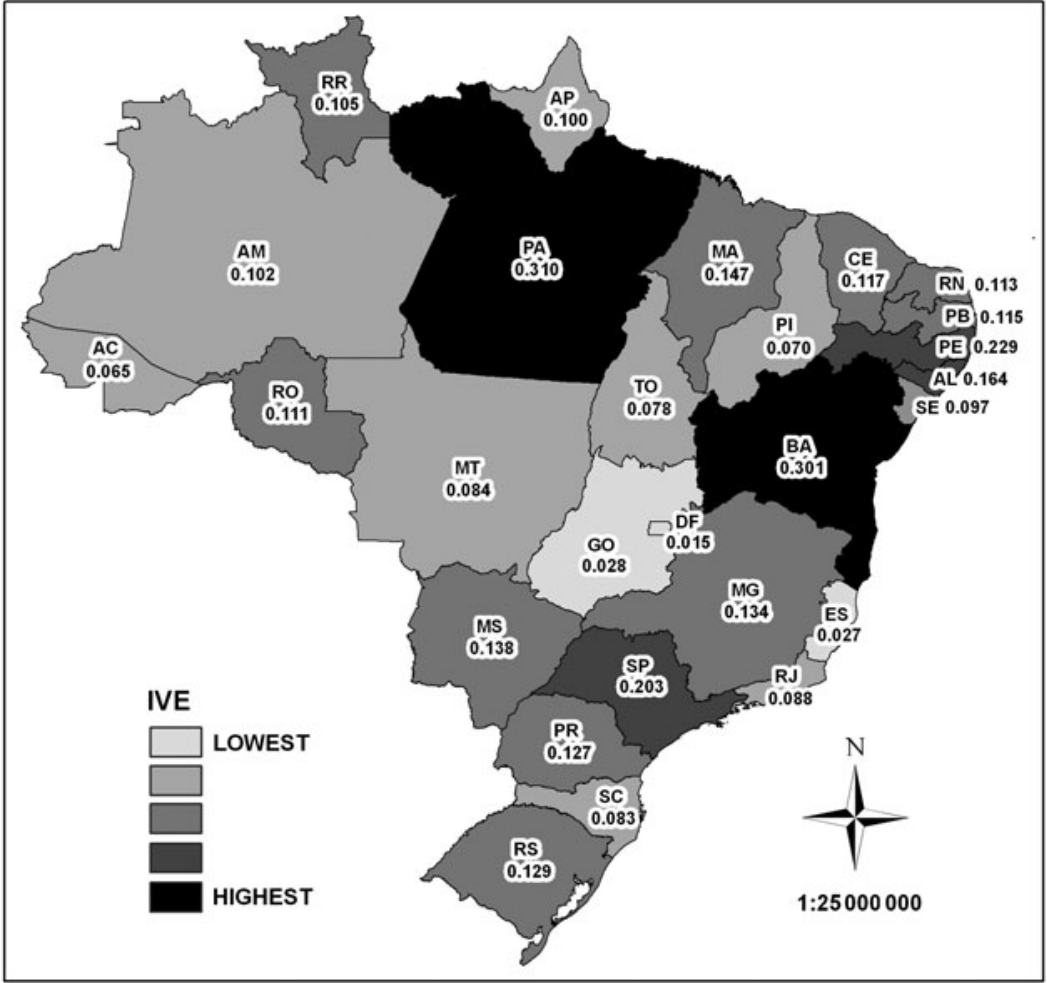

Fig. 3. Epidemiological vulnerability index (IVE) by Brazilian state (abbreviations in Table 3)

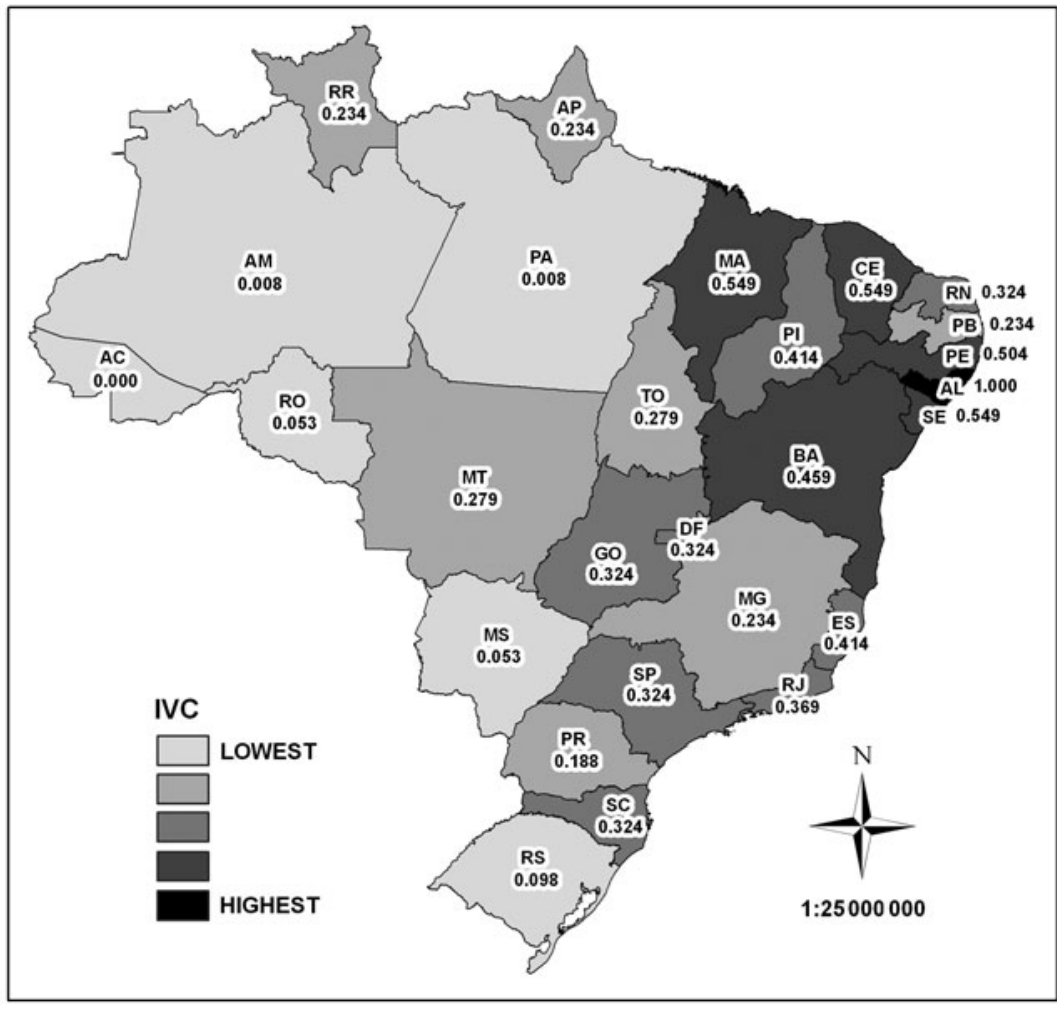

Fig. 4. Climatological vulnerability index (IVC) by Brazilian state (abbreviations in Table 3)
The highest poverty rates were found in the northeastern region: Alagoas (57\%), Maranhão (57\%), Pernambuco (55\%), Piauí $(53 \%)$ and Ceará (52\%). São Paulo and Santa Catarina were the states with the lowest percentages of poor people: 12 and $13 \%$, respectively. The percentage of the population over $15 \mathrm{yr}$ of age, with $<4 \mathrm{yr}$ of school attendance, ranged $15-50 \%$ in the different states, with the lowest degrees of formal schooling in the northeastern region.

More than $95 \%$ of the households in all states in the southern, southeastern and central-western regions were supplied with piped water; only in the states of Amazonas (northern region) and Piauí, Pernambuco and Alagoas (northeastern region) were $<80 \%$ of the houses supplied by this service. As far as effluent disposal was concerned, the states of Maranhão (55.5\% of the households) and Piauí (56.0\%) had the worst conditions, while, in the southern region, >90\% of the households were serviced by some type of sewage collection system. In the southern, southeastern and central-western regions, $>93 \%$ of the households had garbage collection services; this percentage varied between 67.5 and $87.6 \%$ in the northeastern region and 80.6 and $93.7 \%$ in the northern states.

As for infant mortality rates, the states of Rio Grande do Sul and Santa Catarina had the lowest rates: 15.1 and 15.9 per 1000 live births, respectively. On the other hand, the highest rates were observed in the northeastern states: the rate of 62.5 per 1000 live births in the state of Alagoas was much higher than the second highest rate of 49.0 per 1000 live births in Maranhão, also in the northeastern region. Life expectancy at birth ranged from 63.2 yr in Alagoas to $71.6 \mathrm{yr}$ in Rio Grande do Sul (southern region).

The southeastern states like São Paulo (35.8\% of coverage) and Rio de Janeiro $(24.9 \%)$, as well as the Distrito Federal $(25.1 \%)$, had the highest coverage rates of private health insurance. In most of the northern states (except Amazonas), <5\% of the population was covered by health insurance.

With regards to the classification of the Brazilian states according to the IVSE, the lowest socio-economic vulnerability rates were found in São Paulo (0.10) and Santa Catarina (0.15). The low rate for São Paulo 

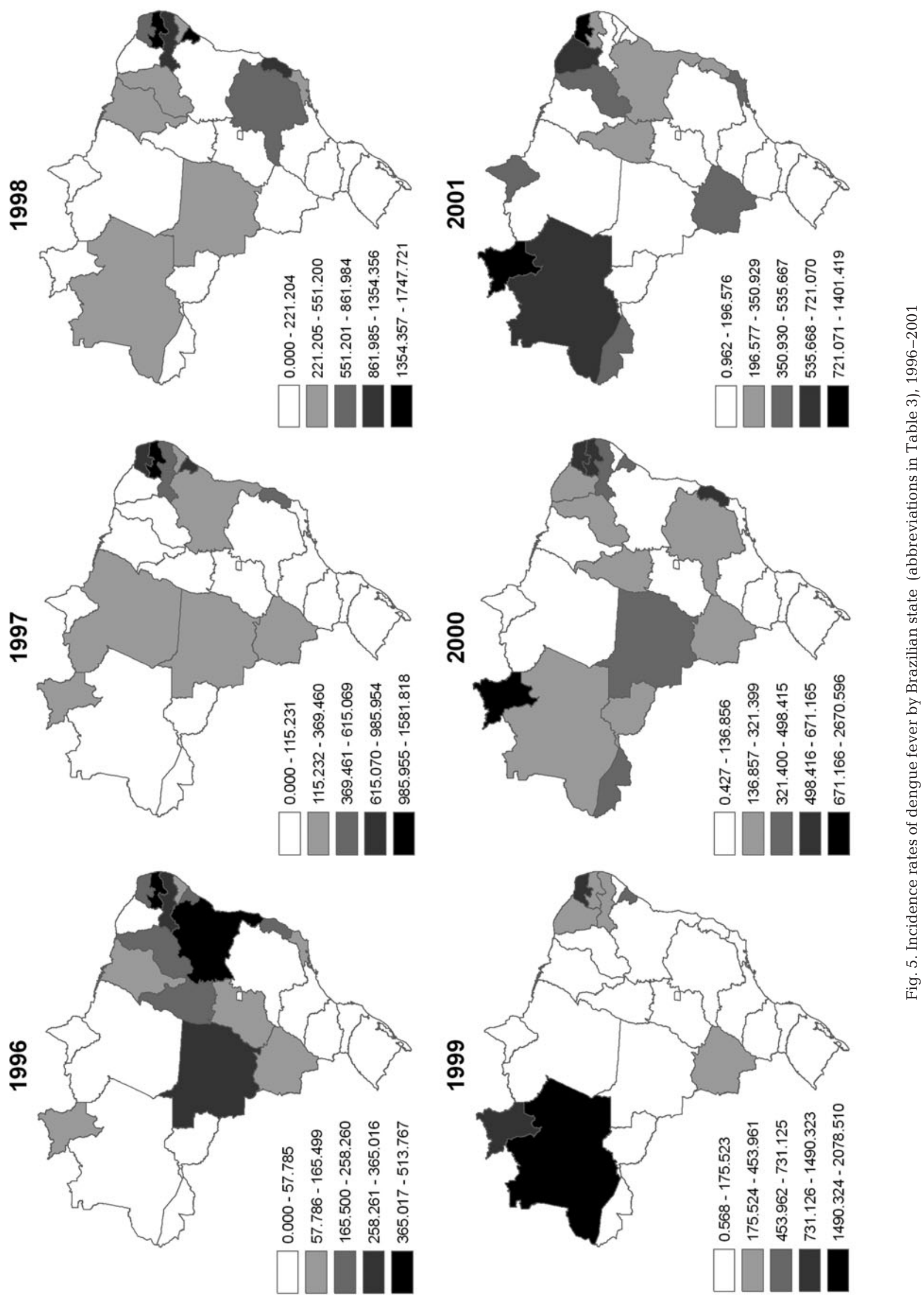
can be explained by its high rate of urbanization (94\%) and low poverty rate $(12 \%)$. It also was shown to have a high rate of formal schooling, when compared to the other states (18\% with < 4 yr of school attendance). São Paulo also had the best rates of sanitation (99.1\% water supply, 98.6\% sewage disposal and 99.1\% garbage disposal) and the third lowest infant mortality rate (17.3 per 1000 live births).

On the other hand, Alagoas (0.76), Maranhão (0.75) and Piauí (0.73) were the states with the highest IVSEs. The poor ranking of Alagoas can be explained by its high demographic density (101.47), the lowest urbanization rate in the country $(68 \%)$, the highest level of poverty $(57 \%)$, a high percentage of the population with poor schooling ( $50 \%$ with $<4$ yr of study) and its poor sanitation services. Furthermore, it had the lowest life expectancy in Brazil (63.2 yr), one of the lowest levels of health insurance coverage (4\%) and the highest infant mortality rate in the country (62.5).

\subsection{Epidemiological vulnerability}

The tropical endemic diseases included in the present study are those that have the greatest relevance as public health problems in Brazil and that have also been historically affected by climate variability and climatic extremes; it is assumed that if they remain uncontrolled, they will be some of the determinants of the future vulnerability of the country to a changing climate.

The incidence rates for the diseases considered here had a discernible pattern of evolution in the $6 \mathrm{yr}$ period of the present study. In the case of dengue fever, the highest incidence rates in the years 1996-1998 were observed in the northeastern region; during 19992001, the highest rates were observed in the northern region (Fig. 5). The other health indicators analyzed (deaths and hospital admissions) showed changes associated with the incidence rates of disease; however, the hospital costs were always higher in the southeastern region, particularly in the state of São Paulo.

The rate of cholera in Roraima and Amapá was 0.00; no cases of cholera were reported in these areas 19962001. The highest rates were observed in Alagoas (0.732) and Pernambuco (0.437), and Alagoas also had the highest disease costs in 4 of the 6 yr of study.

In the case of leptospirosis, the highest indices were in Bahia (0.434), Rio de Janeiro (0.467), Pernambuco (0.478) and São Paulo (0.662). These states have a high demographic density and urbanization rate, factors that can facilitate outbreaks of this disease. As for hantavirus pulmonary syndrome, only 9 states had cases of this disease during the study period, since this condi- tion first emerged in Brazil in 1993. The highest indices were observed in São Paulo (0.270), Rio Grande do Sul (0.361), Paraná (0.399) and Mato Grosso do Sul (0.463). In the southern region, hantavirus cases increased from 4 in 1998 to 52 in 2001, while, in the southeastern region, cases rose from 2 in 1996 to 12 in 2001 and, in the central-western part of the country, 3 cases were observed in 1999 and 11 in 2001. For malaria, higher indices were found in the northern region, the only part of the country where this disease is endemic: 0.824 for Pará, 0.399 for Rondônia and 0.306 for Amazonas. The states with the highest leishmaniasis indices were distributed evenly in 3 regions: northeastern (Bahia, 0.688), northern (Tocantins, 0.272) and southeastern (Minas Gerais, 0.259)

The Brazilian states with the highest IVEs were Bahia and Pará; in the former, the indices for 4 of the 6 diseases were high (dengue fever, cholera, leptospirosis and leishmaniasis), while, in the case of Pará, the high indices for dengue and malaria were responsible for its high IVE. In calculation of the IVE, malaria was heavily weighted, which contributed to a high IVE. States with the lowest IVEs were the Distrito Federal, Espírito Santo and Goiás. In the case of the Federal District, the low IVE can be explained by the very low indices for the 6 diseases (in no case was an individual index >0.01). For Espírito Santo, the state-wide IVE was influenced by the absence of hantavirus infection, by the very low rates of malaria and cholera (0.002), a leptospirosis index of 0.047 and a leishmaniasis index of 0.030 . In the case of Goiás, the highest disease index was for leishmaniasis (0.073), followed by dengue fever (0.046), malaria and hantavirus pulmonary syndrome (0.015), leptospirosis (0.010) and cholera (0.006).

\subsection{Climatological vulnerability}

The greatest precipitation levels in the centralwestern region were associated with the period from November to March, while in the northeastern region most states experienced the highest precipitation values between March and July. In the southern and southeastern regions, the lowest precipitation levels were observed between the months of May and September. The state of Amapá (northern region) had the highest monthly accumulated precipitation intensity in the country; in the months of March and April the monthly rainfall was $>400 \mathrm{~mm}$ (averages: $453.2 \mathrm{~mm}$ in March and $418.9 \mathrm{~mm}$ in April).

In the northern and central-western regions, the highest precipitation levels were up to 10-fold higher than the lowest precipitation levels; in Amapá, the mean value for February was $350.6 \mathrm{~mm}$ compared to only $32.4 \mathrm{~mm}$ for October. Another example is the 
Table 4. Classification of the Brazilian states (abbreviations in Table 3) according to the general vulnerability index (IVG). The classes are given from low to high variability

\begin{tabular}{|lll|}
\hline Class & IVG values & States \\
\hline I & $0.1<$ IVG $\leq 0.2$ & RS, MS, DF, PR, RO, SC, AM, GO, AC \\
II & $0.2<$ IVG $\leq 0.3$ & MG, SP, AP, RJ, MT, ES, RR, PA, TO \\
III & $0.3<$ IVG $\leq 0.4$ & RN, PB, SE \\
IV & $0.4<$ IVG $\leq 0.5$ & PI, CE, PE, BA, MA \\
V & $0.5<$ IVG $\leq 0.7$ & AL \\
\hline
\end{tabular}

precipitation events $(<0.8 \%$ of the observations), despite their high monthly precipitation means. This means that these states showed precipitation levels within the regular and expected pattern.

The IVC has been developed based on the percentage of months with extreme precipitation levels. Alagoas was the state with the highest IVC in comparison with the other states $(\mathrm{IVC}=1.0)$, since it had the highest number of extreme precipitation episodes dur-

state of Goiás, which had a mean value for January of $253.4 \mathrm{~mm}$ as opposed to just $14.2 \mathrm{~mm}$ in June. This situation was completely different in the southern region, where there was much less variability in precipitation throughout the year. In the state of Santa Catarina, for example, the highest mean precipitation level was observed in January (179.6 mm), and the lowest (113.4 mm), in April. The difference between the precipitation in the driest versus the wettest month was $58 \%$.

The number of extreme values calculated for each state corresponded to the sum of all extreme values identified for each month of the year $\left(42 \mathrm{mo}^{-1}\right)$. The state of Alagoas showed the largest number of high values (5.16\% of 504 observations), followed by Sergipe, Ceará and Maranhão. The states of Acre, Amazonas and Pará had the fewest extremely high

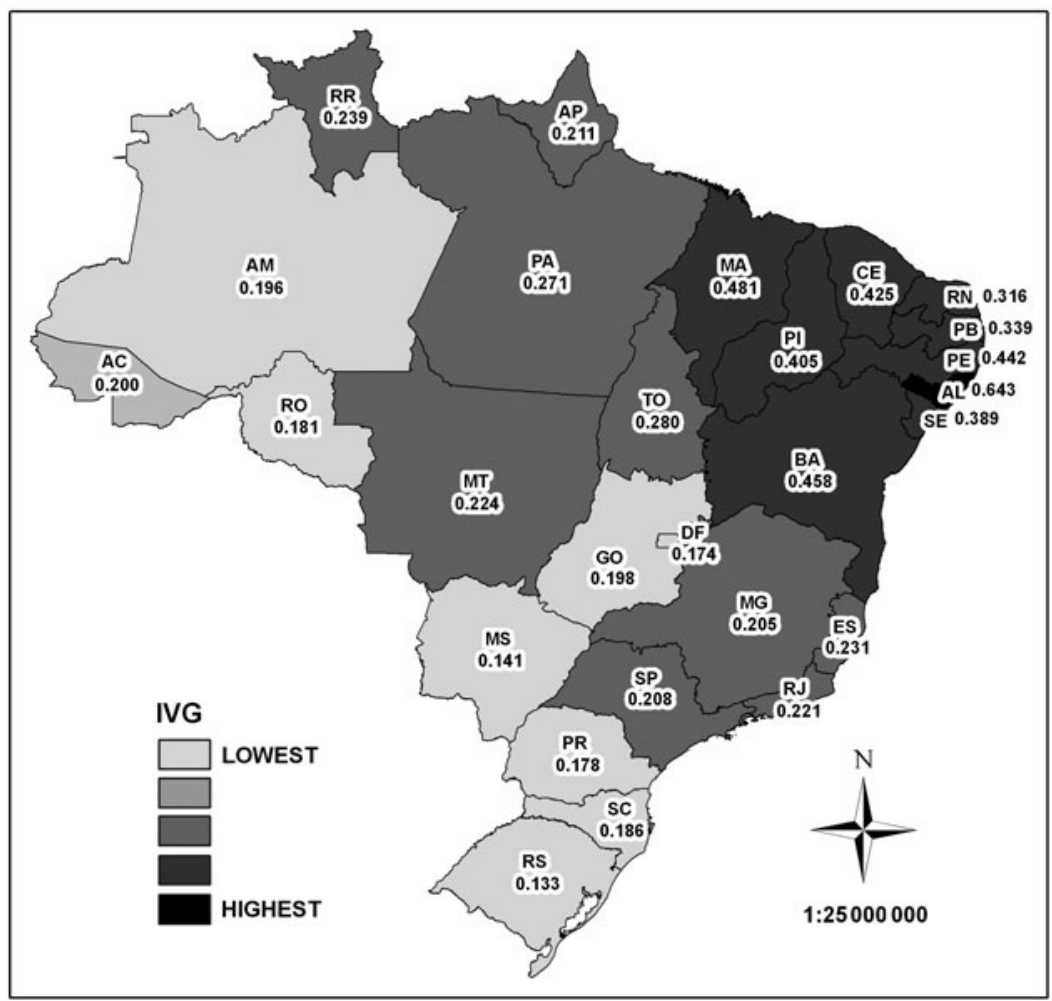

Fig. 6. General vulnerability index (IVG) by Brazilian state (abbreviations in Table 3) ing the study period. The states of Acre, Amazonas, Pará, Mato Grosso do Sul, Rondônia and Rio Grande do Sul had the lowest IVC values, due to the smaller percentages of extreme precipitation values during the period.

\subsection{General vulnerability}

The IVG is the simple mean of the other 3 indices developed in this research. Therefore, it can be interpreted as a measure of the average level of vulnerability of the states. Table 4 shows the classification of the states according to their IVG values. Alagoas was the state with the highest IVG (0.64); this can be explained by its having the worse values for 2 of the 3 indices in the present study: the largest IVSE (0.76) and IVC (1.0) among all states. Furthermore, its IVE value (0.16) is close to the national average.

The second class (IV) with high general vulnerability was formed by 5 states in the northeastern region: Piauí, Ceará, Pernambuco, Bahia and Maranhão. This result was expected, since these states had high values for at least 2 of the 3 dimensional indices. The high vulnerability of this class of states plus Alagoas, also located in the northeastern region, indicated that this was the most vulnerable region of the country. At the other end of the classification spectrum, we have the 3 southern states (Rio Grande do Sul, Santa Catarina and Paraná) as well as the states of Mato Grosso do Sul and Rondônia. The good ranking of these states can be explained by the good individual indices for the southern region, as well as by the low epidemiological and climatological vulnerability of the other 2 states. An IVG of 0.20 was obtained for Amazonas, Acre and Goiás. By grouping the latter states 
with those demonstrating the lowest IVGs, we have a homogeneous group of states in the central, southern and northwestern parts of the country (Fig. 6).

\section{DISCUSSION AND CONCLUSIONS}

Vulnerability assessments at a national level should take into account the regional patterns of vulnerability within the country (Adger et al. 2004). For the present study, we adopted indicators that captured several of the most important biophysical and social determinants of vulnerability. Most of these, such a illiteracy, poverty, sanitation, disease incidence, health expenditure, life expectancy, urbanization and demographic structure have been proposed or used in other assessments (Moss et al. 2001, Orlando \& Klein 2002, Vincent 2004, Brooks et al. 2005, Bhadwal 2006, Thornton et al. 2006, Eriksen \& Kelly 2007).

The International Panel on Climate Change defined vulnerability to climate change as having 3 basic components: exposure, sensitivity and adaptive capacity (IPCC 2001). Ideally, indicators addressing these 3 components should be combined to produce overall measures of vulnerability. The 3 dimensions in our IVG incorporate these 3 components and roughly correspond to each: the IVE reflects sensitivity, the IVC is related to exposure and the IVSE is associated with the determinants of both exposure and adaptive capacity.

Most of the national assessments of vulnerability and the impacts of climate change conducted so far have included some data on the health impacts, but these were usually a secondary concern and were never adequately quantified for comparisons among states, provinces, or municipalities of the respective countries/ provinces. The same is true for the specific health risk assessments associated with climate change (Bolivia Government 2000, Panama Government 2006, United Kingdom Government 2001, Kaumov \& Muchmadeliev 2002, Kovats et al. 2003, McMichael et al. 2003, Thommen Dombois \& Braun-Fahrlaender 2004, Moreno 2005, Zebisch et al. 2005, Bhutan Government 2006, Bresser 2006, Koike 2006, ).

The indices presented here did not measure the degree of vulnerability in relation to ideal situations, and, therefore, an index equal to 0 does not mean the absence of vulnerability; the results must be understood in a comparative sense, considering all Brazilian states. In this vulnerability study we did not include health impacts related to the direct effects of climate extremes, such as storms and floods, because Brazil does not have a reliable national data base on morbidity and mortality related to these events.

The approach used was an operational one, allowing for quantitative comparisons of different geographical units (states) and should be considered a starting point for further vulnerability assessments. These could be developed and expanded by including other components or geographical scales. As an example, for a given country or region, data on malnutrition/food security, water quality/availability, urban atmospheric pollution and morbidity and mortality associated with weather disasters could be included as components of vulnerability. These are aspects also expected to be affected by climate change and are important determinants of human health.

The methods used in the present study could also be applied in the analysis of vulnerabilities for cities or municipalities, provided adequate data series exist. The analysis of vulnerabilities at finer spatial scales could allow the use of more qualitative information, such as livelihood strategies and particular environmental characteristics, which are important aspects of socialenvironmental vulnerability. Socio-economic indicators do not provide enough information on these differential determinants of risks; the population in an urban settlement of squatters in a developing country is vulnerable to the effects of climate for different reasons than small landholders in a rural area of the same country.

From the results obtained with the proposed methodology, the general conclusions that can be drawn are:

1. The northeastern region is most vulnerable in terms of the possible impacts of climate change on tropical infectious diseases. This vulnerability is the result of a combination of poor socio-economic indicators, a semi-arid type of climate prone to extreme variations and the persistence of major endemic infectious diseases in the region.

2. The higher level of socio-economic development in the southern and southeastern regions make them less vulnerable to the effects of climate.

3. Although the vulnerability of the 3 major components were weighted the same in calculations of the IVG, the indices of most of the states with high general vulnerability values were strongly influenced by their IVSE values and, to a lesser extent, by IVC and IVE values.

Acknowledgements. We thank the staff of the 'Global Climate Change Program', of the Brazilian Ministry of Science and Technology (MCT), coordinated by Dr José Miguez, for funding this research and for continuous support.

\section{LITERATURE CITED}

Adger WN, Brooks N, Bentham G, Agnew M, Eriksen S (2004) New indicators of vulnerability and adaptive capacity. Tech. Report 7, Tyndall Center for Climate Change Research, Norwich

Bhadwal S (2006) Indicators of adaptive capacity. In: Thornton PK, Jones PG, Owiyo T, Kruska RL and others (2006) Mapping climate vulnerability and poverty in Africa. ILRI, Nairobi, p 136-145 
Bhutan Government (2006) National Adaptation Programme of Action. National Environment Commission, Royal Government of Bhutan, Thimphu

Blaikie P, Canno T, Davis I, Wisner B (1994) At risk: natural hazards, people's vulnerability and disasters. Routledge, London

Bolivia Government (2000) Vulnerability and adaptation to protect human health from effects of climate change in Bolivia. Programa Nacional de Cambios Climaticos Componente Salud, Viceministerio de Medio Ambiente, Recursos Naturales y Desarrollo Forestal, La Paz

Bresser A (2006) The effect of climate change in the Netherlands. Netherlands Environmental Assessment Agency, MNP, Bilthoven

Brooks N, Adger WN, Kelly PM (2005) The determinants of vulnerability and adaptive capacity at the national level and the implications for adaptation. Glob Environ Change 15:151-163

Confalonieri U (2003) Variabilidade climática, vulnerabilidade e saúde no Brasil. Terra Livre, São Paulo 19:193-204

Eriksen SH, Kelly PM (2007) Developing credible vulnerability indicators for climate adaptation policy assessment. Mitg Adapt Strat Global Change 12:495-524

Few R (2007) Health and climatic hazards: framing social research on vulnerability, response and adaptation. Glob Environ Change 17:281-295

Grimm AM, Natori AA (2006) Climate change and interannual variability of precipitation in South America. Geophys Res Lett 33:L19706 doi: 10.1029/2006GL026821

Hogan D, Marandola E (2005) Towards an interdisciplinary characterization of vulnerability. Popul Space Place 11: $455-471$

IPCC (International Panel on Climate Change) (2001) Climate change: impacts, adaptation, and vulnerability. Summary for policymakers and technical summary of the Working Group II report. WMO/UNEP, Cambridge

IPCC (2007) Climate change 2007: impacts, adaption and vulnerability. Working Group II, 4th assessment report, summary for policy makers. WMO/UNEP, Cambridge

Kasperson RE, Dow K, Archer E, Cáceres T and others (2005) Vulnerable peoples and places. In: Reid W, Mooney $\mathrm{H}_{\text {, }}$ Crooper A (eds) Millennium ecosystem assessment: conditions and trends, Vol 14. Island Press, Washington, DC

Kaumov A, Muchmadeliev B (2002) Climate change and its impacts to the human health. Dushanbe, Avesto

Koike I (2006) State of the art findings of global warming. Contributions of the Japanese researchers and perspective in 2006. In: 2nd report of the global warming initiative, climate change study group. Ministry of Environment Japan, Tokyo

Kovats S, Menne B, Ahern MJ, Patz JA (2003) National assessments of health impacts of climate change: a review, Chap 9. In: McMichael AJ, Campbell-Lendrum DH, Corvalan CF, Ebi KL, Githeko A, Scheraga JD, Woodward A (eds) Climate change and human health. Risks and responses. WHO/WMO/UNEP, Geneva, p 181-203

Liverman D (1990) Vulnerability to global environmental change. In: Kasperson RE, Daw K, Golding D, Kasperson $\mathrm{RX}$ and others (eds) Understanding global environmental change: the contributions of risk analysis and management. The Earth Transformed Program, Clark University, Worcester, MA

Marengo JA (2007) Mudanças climáticas globais e seus efeitos sobre a biodiversidade: caracterização do clima atual e definição das alterações climáticas para o território brasileiro ao longo do Século XXI, Vol 26. Série Biodiversidade, MMA, Brasília

McMichael A, Woodruff R, Whetton P, Hennessy K and others (2003) Human health and climate change in oceania: risk assessment 2002. Department of Health and Ageing, Commonwealth of Australia, Canberra

Moreno J (2005) A preliminary assessment of the impacts in Spain due to the effects of climate change. ECCE project final report. Universidad de Castilla-La Mancha, Ministry of the Environment, Madrid

Moss RH, Brenkert AL, Malone EL (2001) Vulnerability to climate change. A quantitative assessment. Report to the US Department of Energy, Pacific Northwest National Laboratory, Springfield, VA

Nimer E (1989) Climatologia do Brasil. IBGE, Rio de Janeiro

Orlando BM, Klein RJT (2002) Taking an ecosystem approach to climate change adaptation in small island states. Second workshop Climate Change Negotiations. Strategy and Management, Alliance of Small Island States. Apia, Samoa, 31 July-3 August 2000

Panamá Autoridad Nacional del Ambiente (2006) Primera comunicacion nacional sobre cambio climatico, 2000. ANAM, Panamá City

Thommen Dombois O, Braun-Fahrlaender C (2004) Health impacts of climate change with relevance for Switzerland. Insititut fuer Sozial- und Preventivmedizin der Universitaet Basel, Bundesamt fuer Gesundheit, Bundesamt fuer Umwelt, Wald und Landschaft, Basel

Thornton PK, Jones PG, Owiyo T, Krusha RL and others (2006) Mapping climate vulnerability and poverty in Africa. ILRI, Nairobi

Turner BL II, Matson PA, McCarthy JJ, Corell RW and others (2003) Illustrating the coupled human-environment system for vulnerability analysis: three case studies. Proc Natl Acad Sci USA 100:8080-8085

United Kingdom Government (2001) Department of health and expert group on climate change and health in the UK. Health effects of climate change in the UK. Department of Health, London

Vera C, Silvestri G, Liebmann B, González P (2006) Climate change scenarios for seasonal precipitation in South America from IPCC-AR4 models. Geophys Res Lett 33: L13707, doi: 10.1029/2006GL025759

Vincent K (2004) Creating an index of social vulnerability to climate change for Africa. Working Paper 56, Tyndall Center for Climate Change Research, Norwich

Watts MJ, Bohle HG (1993) The space of vulnerability: the causal structure of hunger and famine. Prog Hum Geogr 17:43-67

Zebisch MT, Grothmann D, Schroeter C, Hasse U, Fritsch W, Cramer (2005) Climate change in Germany. Vulnerability and adaptation of climate sensitive sectors. Federal Environmental Agency (Umweltbundesamt), Dessau 